\title{
Mais que paródia? \\ Aquela vez e o teatro tardio de Samuel Beckett ${ }^{1}$
}

\author{
LUCIANO GATTI ${ }^{I}$
}

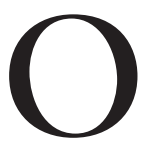

TEATRO PRODUZIDO por Samuel Beckett a partir dos anos 1970 distingue-se nitidamente das peças que fizeram a fama do autor. Beckett dá continuidade à erosão dos fundamentos do gênero dramático iniciada em sua peça de estreia, Esperando Godot (Waiting for Godot, En Attendent Godot [1953]), mas as peças tardias se situam a uma distância ainda maior das convenções dramáticas, caso não as tenham eliminado por completo. Em dimensão reduzida, a cena não apresenta mais personagens em diálogo, como as duplas de Godot e Fim de partida (Endgame; Fin de partie [1957]), mas concentra-se em seres solitários contracenando com uma voz que tende a escapar ao controle, seja o fluxo verbal ininterrupto de Não eu (Not I; Pas moi [1972]), seja a voz em off de Aquela vez (That time; Cette fois [1975]), Passos (Footfalls; Pas [1975]) e Acalanto (Rockaby; Berceuse [1980]). O recurso de cena - a voz mecanicamente reproduzida - acentua a cisão interna da personagem beckettiana, duplicando e exteriorizando a voz pessoal no mesmo passo em que confunde a sua autoria. Reportar-se ao passado, costurando-o ao presente em cena, de modo a constituir uma experiência de vida contínua torna-se uma tarefa ainda mais escorregadia dado o deslizamento constante entre o eu e o outro. Imóveis ou próximos da imobilidade, de corpo inteiro ou recortados (uma boca, uma cabeça), antes fantasmas que figuras de carne e osso, tais personagens acompanham a tendência da redução drástica dos movimentos no palco, que aos poucos se esvai desde os clowns de Godot até a Winnie enterrada na areia de Dias felizes (Happy days; Oh les beaux jours [1961]). A cena tende ao tableau, minuciosamente composto com recursos exíguos, porém precisos, de cenografia e figurino. A imagem pregnante se impõe como presença em cena, mas também é tornada abstrata, fantasmática mesmo, num jogo complexo com as vozes, capaz de suscitar dúvidas a respeito da materialidade mesma das figuras em cena. Tão logo a peça se inicia, as antigas unidades de espaço e tempo, resíduos últimos da literalidade própria à situação teatral, são colocadas em xeque. Por meio de um amplo repertório de procedimentos repetitivos, da reiteração dos movimentos de cena, do ir e vir de um ponto a outro, à retomada constante e alternada das mesmas palavras, dos mesmos fragmentos de episódios passados, personagens e histórias ensaiam continuidades, mas nunca se aglutinam num todo coeso. No âmbito depurado 
do teatro tardio, mais que o questionamento, tem-se a resistência mesma à configuração de identidades e unidades narrativas.

As peças tardias colocavam questões novas a respeito da constituição do espetáculo teatral. Caracterizar o novo é também pensar a atualidade da reflexão produzida e sedimentada em teorias e conceitos. Não é por outro motivo que a reflexão teatral volta e meia retorna ao conceito de drama. No caso de Beckett é de especial interesse a reflexão proposta por Adorno ao analisar Fim de partida como uma paródia do drama (Gatti, 2014). De modo geral, o conceito de paródia é um termo-chave do modernismo em seu olhar para o passado. Em outras palavras, ela é um sinal da consciência histórica a respeito da inviabilidade dos materiais e formas da tradição. Se as convenções permitiam prever que o conflito entre os personagens, exposto formalmente no diálogo, encaminharia a ação, primeiro, para a intensificação do conflito e, depois, para sua resolução, conferindo unidade ao conjunto, Fim de partida subverte o sentido do drama enquanto gênero. Ao se valer do conceito de paródia, Adorno observa que os elementos constitutivos do drama comparecem em Fim de partida, mas compondo uma espécie de atestado de óbito do gênero:

Elas [as categorias dramáticas] são todas parodiadas. Mas não se zomba delas. De maneira enfática, a paródia se define pela utilização de formas na época de sua impossibilidade. Ela demonstra essa impossibilidade e transforma deste modo as formas. As três unidades aristotélicas são conservadas, mas o drama mesmo perece. Assim como ocorre com a subjetividade, cuja representação póstuma é Fim de partida, também o herói é abandonado; da liberdade só se conhece aquele reflexo impotente e ridículo de decisões que não são nada. (Adorno, 1999, p.302-3)

Embora a paródia caracterize os diferentes matizes do conflito entre Hamm e Clov, senhor e servo, Adorno privilegia o exemplo da "esticomitia", uma técnica de alternância acelerada entre personagens do diálogo cuja função era intensificar a ação dramática. Fim de partida retoma esse procedimento, mas os diálogos alternados, monossilábicos, não instauram tensão em vias de uma resolução. Ao contrário, o ânimo arrefece, as personagens perdem o fôlego, o diálogo fraqueja no ritmo até o emudecimento que dissolve a tensão dramática e reinstaura o vazio na administração do tempo presente. O fim do drama, sua conversão em paródia de si mesmo, pode ser lido então como cifra deste processo tanto histórico quanto artístico. Se Clov não se liberta do domínio de Hamm, abandonando o refúgio e conferindo sentido retrospectivo ao conflito com seu senhor, é porque tal ação exigiria as condições de exercício da liberdade disponíveis ao herói do drama burguês, mas não a esses habitantes do refúgio de Fim de partida. A resolução da ação não é uma constelação possível diante da situação histórica atual do drama.

Como se vê, a paródia condensa para Adorno uma crise do drama que não promete superação, uma vez que essa exigiria condições de liberdade inexistentes segundo o diagnóstico adorniano do mundo administrado. Nesse senti- 
do, Adorno entende o teatro beckettiano como uma resposta mais consequente à crise do drama do que tentativas de superação em novas formas, tal como pretendia o teatro épico brechtiano. Assim como Fim de partida, o teatro não aristotélico de Brecht também guardava uma referência ao drama, mas não como paródia, e sim como a sua negação determinada. Diante desse quadro, a questão colocada pelo teatro tardio de Beckett é a da pertinência do conceito de paródia para a caracterização da experiência que delineiam. Beckett referia-se às suas peças tardias como "dramatículos", um termo que trai vestígios de tradição, cabeira perguntar se reportam-se ao gênero dramático da mesma maneira que Fim de partida. Caso contrário, seriam superações do drama num sentido análogo ao proposto pelo épico ou configuram o meio teatral de um modo irreconhecível à luz do passado?

Que a questão é intrincada, não há dúvida. Neste artigo, eu gostaria de encaminhar a discussão colocando em foco uma peça em particular, Aquela vez. A dificuldade de abordá-la pelo viés da crise do drama e de suas tentativas de superação pode ser exemplificada pela posição ambígua que tal peça ocupa no Teatro pós-dramático de Hans-Thies Lehmann. Esse livro, um marco recente dos estudos teatrais, propõe a superação do drama por um teatro mais próximo das artes performáticas e visuais, distante portanto da encenação que tem por parâmetro a representação de um universo ficcional. "Pós-dramático", portanto, não é apenas um teatro crítico dos parâmetros do drama burguês ou aristotélico, como, de resto, o teatro brechtiano já o era, mas também um teatro para o qual o texto não é mais que um dos muitos elementos constitutivos do espetáculo. Nesse contexto, Lehmann considera as peças tardias de Beckett como pós-dramáticas, situando-as portanto após a ruptura proposta por seu livro. A sua análise de Aquela vez é, contudo, inteiramente conduzida pelo conceito de paródia, a saber, a paródia das unidades da tragédia clássica francesa.

Assim como ocorre em outras peças de Beckett, em Aquela vez há uma unidade de lugar e de tempo, mas ela é - evidentemente - parodiada. Nada daquilo que está associado à unidade de tempo no teatro dramático se aplica aqui. O que há não é exatamente uma unidade, mas uma desagregação da vivência do tempo. O fio da continuidade interna é rompido. (Lehmann, 2008, p.298-9)

Esse conceito de paródia parece menos carregado de história que o de Adorno, pois, se Aquela vez não admitisse mesmo nada daquilo tradicionalmente associado às unidades de tempo e lugar, por que caracterizar a peça como paródia do drama classicista? Lehmann defende a ruptura com o drama, mas para tal utiliza um conceito que pressupõe o vínculo: ao contrário do pastiche, a paródia implica alguma referência normativa ao termo parodiado (ao menos em sentido adorniano). O importante aqui é notar que Lehmann - involuntariamente, vale dizer - explicita a dificuldade em caracterizar tais peças, ou ao menos em abordá-las pelo viés das negativas implicado no conceito de pós-dramático. Vejamos a peça. 
Escrita em inglês entre 1974 e 1975, estreada em Londres em 1976 com direção de Donald McWhinnie e Patrick Magee no papel de ouvinte, Aquela vez traz em seu título, segundo Ackerley e Gontarski, uma combinação da Ode à Imortalidade de Wordsworth ("Aquele tempo é passado") com o soneto LXXIII de Shakespeare ("Podes ver em mim aquela época do ano"). Ainda nas alusões intertextuais, a peça retomaria o texto dos Provérbios (26:11): "Como o cão que torna a seu vômito / é o insensato que repete a sua idiotice”. Nos primeiros esboços, tal idiotice (Folly) é identificada à "Torre de Barrington", depois alterada por aliteração para "Foley's Folly", referência a um esconderijo de infância ao qual o personagem tenta em vão retornar quando adulto (Ackerley; Gontarski, 2006, p.599). Em carta a George Reavey, Beckett menciona que concebeu Aquela vez como uma "peça-irmã" de Não eu. Nessa última, escrita em 1972, "ela fala"; em Aquela vez, "ele ouve". ${ }^{2}$ Enquanto uma apresenta apenas a cabeça e os longos cabelos brancos do ouvinte, disposto em cena como se visto de cima, a outra limita-se à boca em fala ininterrupta ao lado do seu "auditor". Imagens concisas mas eloquentes, recortes do corpo mergulhados na escuridão: quando interrogado, durante os ensaios para a estreia de Aquela vez, a respeito da desproporção entre o palco e a dimensão reduzida da cabeça, Beckett sustentou o princípio de que "menos é mais", e que ela poderia ser ainda menor. ${ }^{3}$ À direita, à esquerda e acima do ouvinte, três alto-falantes reproduzem alternadamente a voz de um mesmo ator que interpela o ouvinte na segunda pessoa do singular com fragmentos de três histórias independentes, enquanto o interroga (ou se interroga) a respeito da localização das histórias no tempo: "aquela vez", "quando foi aquilo", "foi aquela vez ou aquela foi outra vez". Apenas duas pausas de dez segundos cada interrompem as vozes, ocasião em que o ouvinte abre os olhos para então tornar a fechá-los pouco após recomeçarem; ao final, quando silenciam, ele sorri por cinco segundos antes de as luzes se apagarem. É esta alternância constante de três vozes, de três histórias independentes, que daria corpo ao que Lehmann chama de "desagregação da vivência do tempo".

A voz "A" recorda a tentativa frustrada de retornar ao antigo esconderijo da infância, "Foley's Folly". Ele reencontra os velhos trilhos, mas os bondes aparentemente não circulam mais.

[...] aquela vez você voltou daquela última vez para ver a ruína ainda estava lá onde você criança se escondeu quando foi aquilo [os olhos fecham] dia cinza tomei o onze até o fim da linha e dali em diante nenhum bonde todos se foram muito tempo atrás aquela vez em que você voltou para olhar a ruína ainda estava lá onde você criança se escondeu daquela última vez mais nenhum bonde no lugar só os velhos trilhos quando foi aquilo. (Beckett, 1990$, p.388 $)^{4}$

A fala repetitiva, que mimetiza o esforço tateante de reencontrar e narrar o passado, também confunde temporalidades, pois "aquela vez" é, a um só tempo, o tempo da criança escondida nas ruínas de Folly, na companhia de seus 
livros e de conversas imaginárias enquanto a família a procura, o tempo da errância do homem adulto em busca pelo local do passado, assim como o tempo de um narrador, seja ele o viajante frustrado que aguarda o trem de retorno, seja a voz que narra ao ouvinte em cena:

$[\ldots]$ inventando agora uma voz agora outra [...] inventando agora no degrau da porta enquanto você continuava se inventando todo de novo pela milionésima vez esquecendo tudo onde você estava e para quê Foley's Folly e o entorno a ruína da criança você veio procurar ainda estava lá para se esconder de novo até a noite chegar e ser hora de ir embora até que aquela vez chegou. (Beckett, 1990, p.394) ${ }^{5}$

Como Ackerley e Gontarski comentam, o retorno, embora frustrado, termina por remeter o adulto à situação da infância solitária, em busca de histórias nas quais possa se reencontrar: "ele se encontra mais uma vez no lugar, recriando a experiência da infância (como o autor, talvez), inventando histórias, uma voz e então mais uma" (Ackerley; Gontarski, 2006, p. 569). Memória e invenção, passado e presente, se entrelaçam no ato de narrar levado a cabo como uma busca por companhia, tema-chave também da prosa tardia de Beckett.

Sem continuidade explícita com a história de A, o tema da busca por um outro reaparece na voz "B", dessa vez sob a figura do encontro amoroso frustrado.

[...] na pedra juntos sob o sol na pedra à beira da pequena floresta e tão longe quanto os olhos podiam ver o trigo ficando amarelo jurando a todo momento vocês amavam um ao outro só um murmúrio sem tocar nem nada parecido. (Beckett, 1990, p.388) ${ }^{6}$

Assim como o esconderijo de infância, a imagem de ambos sentados lado a lado na paisagem natural também é objeto de um relato constituído posteriormente. Em momentos distintos, espaçados no tempo, em que o narrador se encontra ora deitado na areia ora sentado no escuro diante de uma janela, o recurso à narração é mais uma vez a contrapartida de uma busca não consumada:

[...] ou diante da janela no escuro ouvindo a coruja nem um pensamento na sua cabeça até ficar difícil de acreditar mais e mais difícil de acreditar você nunca contou a ninguém que os amava ou alguém você até só uma daquelas coisas que você ficava inventando para escapar do vazio só mais uma daquelas velhas histórias para evitar que o vazio te cobrisse com a mortalha [...] ou sozinho nas mesmas nas mesmas cenas inventando daquele jeito para continuar continuar na pedra [olhos fecham] sozinho no fim da pedra [...] or by the window in the dark harking to the owl not a thought in your head till hard to believe harder and harder to believe you ever told anyone you loved them or anyone you till just one of those things you kept making up to keep the void out just another of those old tales to keep the void from pouring in on top of you the shroud [...] or alone in the same the same scenes making it up that way to keep it going keep it out on the stone [Eyes close.] alone on the end of the stone. (Beckett, 1990, p.390) ${ }^{7}$ 
Por último, a voz C interpela o ouvinte com a história de um homem decrépito, próximo ao desespero, que se abriga da chuva na National Portrait Gallery de Londres. Sentado diante de um retrato, o reflexo da tela provoca-lhe um choque, confundindo a sua imagem com a do retratado. O abalo da própria identidade é tanto um "ponto de viragem" quanto uma experiência recorrente para um "eu" constantemente colocado à prova.

[...] você já disse eu alguma vez pra você mesmo na sua vida vamos lá [olhos fecham] você poderia alguma vez dizer eu para você mesmo no ponto de virada da sua vida essa era uma palavra e tanto [...] sem saber quem estava dizendo o que você estava dizendo na caveira de quem você estava trancado no lamento de quem você era do que jeito que era daquela vez ou era aquela outra vez sozinho com os retratos dos mortos pretos de sujeira e antiguidade e as datas nas molduras para o caso de você errar o século sem acreditar que poderia ser você até eles te colocarem para for a na chuva na hora de fechar. (Beckett, 1990, p.390-1) ${ }^{8}$

Experiências semelhantes de descentramento do eu ocorrem no correio, onde ele é acometido pela sensação de não existir ao passar despercebido, e na biblioteca, cujas estantes forradas de livros o afetam com a experiência do pó que tudo recobre: "quando você abriu os olhos do chão ao teto nada além do pó". Ackerley e Gontarski reconhecem aí tanto a advertência de Deus a Adão ("pois tu és pó e ao pó tornarás") quanto o pressentimento da morte próxima, do movimento incessante de ir e vir desaparecendo com o tempo: "desaparecido em tempo algo algum desaparecido em tempo algo algum" (Ackerley; Gontarski, 2006, p.569-70). É o que torna a voz C ainda mais enfática no fracasso do encontro consigo mesmo.

Se a referência topográfica confere algum lastro às lembranças evocadas, aglutinando-as em um local demarcado (a ruína, a pedra no campo, a biblioteca), que pode ser posteriormente buscado ou visitado, a indeterminação temporal ("quando foi isso") chama a atenção para os laços esgarçados entre presente e passado. Durante os ensaios para a sua encenação da peça em Berlim, em 1976, Beckett forneceu duas indicações nesse sentido. A primeira delas a respeito das vozes. Embora cada uma remontasse a um período da vida do ouvinte, sendo gravadas pelo mesmo ator com entonações ligeiramente distintas, ele insistiu que fossem encadeadas em um fluxo contínuo, sem pausas. Veja-se o relato de Walter Asmus, assistente de direção de Beckett na ocasião:

Entre A, B, C deve haver uma transição sem interrupção, como, por exemplo, na música, de Lá menor para Dó maior, diz Beckett; um fluxo sem começo e fim, sem que se enfatize ou se assinale muita coisa. [...] Beckett mesmo demonstra o modo de falar: plano, respirando sem ruídos, murmurando, sonhador, sem qualquer interrupção perceptível, ele passa por toda uma fala sem parar. [...] Se alguém pudesse passar sem cortes, mantendo o mesmo andamento constantemente, seria o melhor... (Asmus, 1986, p.346-7) 
Como os momentos do passado não se encadeiam de modo cronológico, mas pelo embaralhamento repetitivo de momentos distantes no tempo, qualquer noção de continuidade torna-se problemática. A segunda indicação acentua o mesmo ponto, dessa vez pela alternância entre as vozes e os momentos de silêncio em que o ouvinte abre os olhos.

Beckett comenta o silêncio após cada uma das três partes: nesses momentos, o homem retorna ao presente. Enquanto ele ouvia a sua voz, ele estava no passado. Durante a escuta tudo está fechado. No silêncio, ele fica surpreso ao encontrar-se no presente; tudo está aberto. Não é claro se ele abre os olhos e a voz para por esse motivo ou se a voz para e, portanto, abre os olhos. (Asmus, 1986, p.348)

Esses arranjos por meio da exteriorização mecânica das vozes tendem a frustrar as expectativas convencionalmente associadas à memória: não se tem mais uma apropriação dos eus passados pelo eu presente, que os reúne conferindo-lhes identidade, mas uma polifonia de três vozes que, cada uma à sua maneira, trabalham a partir da cisão entre o eu das lembranças passadas e o ouvinte no presente da encenação. Questões transversais às três vozes, como a busca por si e por companhia ou o hábito de contar histórias, se fornecem pontos de contato, também reafirmam o estranhamento entre o eu e o outro, entre presente e passado. Casualmente associadas à figura em cena, as narrativas não se atualizam em uma "ação dramática no agora do palco", como diz Lehmann. Embora as três vozes sejam interlocutoras da mesma figura em cena, não há solução de continuidade entre elas. $\mathrm{O}$ sequenciamento rigoroso ( $\mathrm{ACB}, \mathrm{CAB}, \mathrm{CBA}, \mathrm{BCA}, \mathrm{BAC})$ em três sessões de 5 minutos, intercaladas por uma pausa de 10 segundos, contribui mais para a autonomia das vozes que para a sua unidade. Tal desagregação problematiza a continuidade própria à experiência, favorecendo a dispersão dos dados isolados, ouvidos como histórias que, dada a exterioridade da reprodução mecânica, apresentam-se em sua alteridade ao sujeito dessa experiência, como vivências de outros. A relação entre voz e ouvinte assemelha-se aqui àquela apresentada por Beckett em Eh Joe, sua primeira peça televisiva. Se lá a alteridade da voz era bem marcada pelo emprego de uma voz feminina interpelando o personagem masculino, em Aquela vez, ela é acentuada pela cisão da identidade da experiência em vozes autônomas. Por fim, o sorriso diante do silenciamento das vozes, que aparece também em Eh Joe (Eh Joe [1965]) e em Trio-Fantasma (Ghost-Trio [1975]), caso indique a vitória do eu em luta contra a alteridade da voz, também pressupõe a clivagem entre personagem e narrativa.

Voltando à leitura de Lehmann, tais cisões são perpassadas pelo tema comum da busca frustrada de um tempo perdido: a voz A busca "o tempo de um passado individual, pessoal, um tempo da infância"; a voz B, o "o tempo da natureza, do encontro sexual"; e a voz C, "a continuidade de um suprapessoal tempo da cultura, do contexto social, da tradição - daí os velhos retratos no museu, a biblioteca, o sistema social da escrita, o correio" (Lehmann, 2008, p.299). O fracasso nos três casos é interpretado como resultado da desagregação 
da identidade subjetiva, selo da "morte do indivíduo" colocada em cena pela disjunção polifônica entre falar, ouvir e ouvir-se falar. Como já foi indicado, os recursos para encenar esse diagnóstico decorrem da tradição, pois a redução beckettiana é, a seu ver, uma paródia da redução classicista:

A estética da redução do teatro classicista, especialmente o de Racine períodos de tempo mínimos, lugar único, concentração em um conflito quase que puramente espiritual, com a tendência de supressão de qualquer elemento real que preencha o espaço e o tempo -, retorna modificada na radical dramaturgia do ponto zero de Beckett. [...] Seus personagens levam uma existência espiritual quase que incorpórea - paródia da abstração e da espiritualização clássicas. (Lehmann, 2008, p.299-300)

Lehmann chama a atenção para a impossibilidade da redução clássica, pois ela produzia algo em cena por meio da "colisão dramática". Na ausência do tradicional conflito entre individualidades, resta a paródia como resposta adequada a um tempo de ruínas. É surpreendente como o conceito de paródia termina por situar a interpretação de Lehmann não tanto no terreno de um teatro "pós-dramático", mas em estreita continuidade com a leitura de Fim de partida proposta por Adorno. É o que dá a entender seu comentário da imagem da biblioteca recoberta de pó com que Beckett conclui a peça: “Tempo algum, apenas partículas. A decomposição e a pulverização da dimensão temporal manifestam a desagregação e a morte do indivíduo, $\mathrm{O}$ pó do tempo cultural que estava acumulado em milhões de páginas de livros e agora tolhe a vista - apenas isso resta do tempo como forma da experiência” (Lehmann, 2008, p.300).

Sob o signo do fracasso, a leitura de Lehmann, em alguma medida, tende a unificar os momentos dispersos ao tomar a imagem da biblioteca como o arremate da peça que "sela o desastre" para o indivíduo e para a cultura. O que "resta do tempo como forma da experiência" é a desagregação mesma de uma concepção de experiência constituída pela recapitulação dos momentos constitutivos de uma vida inteira. Que a obra de Beckett extraia força do declínio de uma noção tradicional de experiência, não há dúvida, mas seria essa a história inteira? Embora a referência paródica à tradição confira lastro histórico e reflexão formal a seus esforços, cabe perguntar se a redução beckettiana não sugere também que o estado de desagregação seja o meio mesmo da constituição da experiência no presente. Em outros termos, não mais experiência como a interiorização retrospectiva de continuidades, mas, tal como um paradoxo em movimento, a experiência como a busca por articulações transitórias de instantes dispersos apreendidos em sua exterioridade. Essa seria uma formulação mais próxima da conjunção entre o que o espectador escuta e o que vê em Aquela vez. Colocar em relação fragmentos desconexos, justapô-los sem unificá-los, repeti-los em configurações diversas sem término à vista, oscilando entre a expectativa de conclusão e impossibilidade de que a "história seja contada": tem-se aí as forças de atração e repulsão que conferem dinamismo à produção tardia de Beckett, como pode evidenciar uma 
incursão mais detida por seu teatro. Não por acaso, essa dialética também dá nome à peça inaugural do teatro tardio de Beckett: Não eu.

A negação da primeira pessoa enuncia uma cisão fundamental na constituição da personagem beckettiana, a qual encontrará na relação entre a figura em cena e a voz em off uma forma privilegiada de exposição. Nesse terreno em que o indivíduo em crise é moeda corrente, Beckett confronta a desagregação da experiência ao buscar conexões transitórias e dissonantes de vozes que se alternam e se repetem, simultaneamente em alusão e resistência a continuidades que nunca se verificam por completo. Se outrora o drama era motor e representação do destino individual, recapitulando o todo no desfecho conclusivo, seriam os dramatículos de Beckett ainda uma paródia do gênero? Eis nosso ponto de partida. As peças examinadas deixaram para trás as convenções do drama: os personagens não tem contornos precisos, as narrativas do passado invadem e desmancham a atualidade viva do presente dramático, as vozes se autonomizam das figuras em cena por meio da reprodução mecânica, o tempo avança apenas na medida da repetição, nenhum vestígio, em suma, da imitação de uma ação completa, antigo modelo do drama. Se ainda são textos para teatro, não são mais textos dramáticos. Adentram então o terreno do pós-dramático?

Vale aqui arriscar uma hipótese antes de concluir. Se as convenções dramáticas são terra arrasada, o conflito, por sua vez, aguilhão mesmo do drama, mantém-se presente nas conexões buscadas entre os elementos de uma experiência em desagregação, da justaposição de vozes e narrativas ao embaralhamento de temporalidades. Mas essa é uma busca que se configura nos processos de encenação, não mais no drama enquanto tal. Os conceitos de paródia e de pós-dramático, por sua vez, pressupõem uma abordagem das peças pelo viés do drama. Por esse motivo não dão conta dos dramatículos de Beckett, os quais não são propriamente nem um novo gênero de escrita teatral, para além do drama, nem uma forma de teatro alheia aos problemas colocados pela história do drama. ${ }^{9}$ Diante disso, arriscaríamos dizer que o alcance do teatro beckettiano estaria em conceber os processos de encenação como responsáveis por dar forma aos problemas oriundos do rompimento da unidade interna ao drama. Em outras palavras, os meios de encenação se valeriam de textos não dramáticos para problematizar questões que foram uma vez postas pelo drama, tais como indivíduo, conflito e experiência. Daí a dimensão maior dessas peças como fenômenos cênicos, em que o texto, este velho produtor dos sentidos, tem suas funções dadas pela encenação, colaborando na apresentação de identidades cindidas e relativizando a evidência literal da presença em cena.

$O$ recurso reiterado à voz em off é especialmente propício à discussão desse drama de segundo grau produzido pelas práticas de encenação. Dispositivo cênico imprescindível ao teatro tardio, ela é impensável sem a experiência de Beckett com outros meios artísticos, em particular a voz "desencarnada" das peças para o rádio e para a televisão Do mesmo modo, a cena fortemente pictórica 
deve muito à composição de imagens televisivas. Beckett lidou simultaneamente com diversos meios artísticos, mas é característico de seu trabalho que as reverberações de um meio sobre outro não resultem em hibridismo formal. Muito pelo contrário, elas tendem a acentuar a especificidade de cada um dos meios empregados. Seu teatro vai assim na direção contrária da cena expandida pela música, pela dança e pela performance em espetáculos híbridos, contemporâneos a ele, analisados por Lehmann pelo viés do pós-dramático. Ele não apenas se manteve à distância de tendências intermediais como também não via com bons olhos as tentativas de adaptação de suas obras de um meio para outro. ${ }^{10}$ Seria então Beckett um modernista aguerrido em defesa da autonomia dos meios? Somente se a autonomia também implicar a possibilidade de negação imanente dos meios. É o que Beckett propõe ao fazer da encenação o âmbito expandido para uma autorreflexão a respeito da experiência obsoleta do drama.

\section{Notas}

1 Agradecimento - O presente artigo resulta de pesquisa financiada pela Fundação de Amparo à Pesquisa do Estado de São Paulo (Fapesp) na modalidade “Auxílio Regular".

2 Carta de Beckett a George Reavey de $1^{\circ}$ de setembro de 1974 (apud Ackerley; Gontarski, 2006, p.598). Estranhamente esta carta não consta da edição das cartas de Beckett editadas pela Cambridge University Press.

3 The theatrical notebooks: the short plays (Gontarski, 1999, p.360). Os cadernos de encenação de Beckett trazem indicações de mudanças de iluminação (luz forte durante as pausas, meia-luz durante a escuta das vozes) e variações dos padrões de alternância das vozes.

4 As traduções da peça de Beckett são de minha responsabilidade. Para comparação com o original, deixo em notas a versão inglesa. "that time you went back that last time to look was the ruin still there where you hid as a child when was that [Eyes close] grey day took the eleven to the end of the line and on from there no trams then all gone long ago that time you went back to look was the ruin still there where you hid as a child that last time not a tram left in the place only the old rails when was that".

5 "making it up now one voice now another...", "making it all up on the doorstep as you went along making yourself all up again for the millionth time forgetting it all where you were and what for Foley's Folly and the lot the child's ruin you came to look was it still there to hide in again till it was night and time to go till that time came".

6 "on the stone together in the sun on the stone at the edge of the little wood and as far as eye could see the wheat turning yellow vowing every every now and then you loved each other just a murmur not touching or anything of that nature".

7 "or by the window in the dark harking to the owl not a thought in your head till hard to believe harder and harder to believe you ever told anyone you loved them or anyone you till just one of those things you kept making up to keep the void out just another of those old tales to keep the void from pouring in on top of you the shroud [...] or alone in the same 
the same scenes making it up that way to keep it going keep it out on the stone [Eyes close.] alone on the end of the stone".

8 "did you ever say I to yourself in your life come on now [Eyes close.] could you ever say I to yourself in your life turning-point that was a great word [...] no notion who it was saying what you were saying whose skull you were clapped up in whose moan had you the way you were was that the time or was that another time there alone with the portraits of the dead black with dirt and antiquity and the dates on the frames in case you might get the century wrong not believing it could be you till they put you out in the rain at closing-time".

9 A irredutibilidade de Beckett ao pós-dramático é análoga àquela de Heiner Müller, ironicamente o dramaturgo mais associado por Lehmann ao conceito. Cf. Luciano Gatti (2015).

10 A adaptação da prosa para o palco é um interessante capítulo da recepção de seu trabalho, muito bem discutido por Jonathan Kalb (1989, especialmente o cap.7).

\section{Referências}

ACKERLEY, C. J.; GONTARSKI, S. E. (Ed.) The Faber Companion to Samuel Beckett. London: Faber and Faber, 2006.

ADORNO, T. W. Versuch, das Endpiel zu verstehen. In: . Noten zur Literatur. Frankfurt am Main: Suhrkamp, 1999.

ASMUS, W. Rehearsal notes for the German premiere of Beckett's That Time and Footfalls. In: GONTARSKI, S. E. (Ed.) On Beckett: Essays and Criticism. New York: Grove Press, 1986.

BECKETT, S. That Time. In: The Complete Dramatic Works. London: Faber and Faber, 1990.

GATTI, L. A peça de aprendizagem. Heiner Müller e o modelo brechtiano. São Paulo: Edusp, 2015.

Adorno e Beckett. Aporias da autonomia do drama. Kriterion, Belo Horizonte, v.5, n.130, Dec. 2014.

GONTARSKI, S. E. The Theatrical Notebooks of Samuel Beckett, v.4, The Shorter Plays. London: Faber and Faber; New York: Grove Press, 1999.

KALB, J. Beckett in performance. Cambridge: Cambridge University Press, 1989.

KNOWLSON, J. Damned to Fame. The Life of Samuel Beckett. New York: Grove Press, 1996.

LEHMANN, H.-T. Teatro pós-dramático. São Paulo: Cosac Naify, 2008.

RESUMO - O artigo propõe um debate a respeito do teatro tardio de Samuel Beckett a partir do conceito de paródia, tal como utilizado por Theodor W. Adorno e Hans-Thies Lehmann para pensar tanto a crise do drama quanto as possibilidades de sua superação. Nesse contexto, a peça Aquela vezé analisada como um caso singular de seu teatro tardio. As relações entre memória e narrativa na experiência individual, tais como propostas pelo texto beckettiano, são examinadas à luz do emprego da voz em off como 
recurso de encenação. Com base nesses elementos, o artigo discute a pertinência do conceito de paródia para o teatro tardio de Beckett.

PALAVRAS-CHAVE: Samuel Beckett, Drama, Teatro contemporâneo, Paródia.

ABSTRACT - The paper proposes a debate on Samuel Beckett's later theater based on the concept of parody, as discussed by Theodor W. Adorno and Hans-Thies Lehmann, as a reflection both on the crisis of drama and on the possibilities of overcoming it. In this context, the play That Time is analyzed as a singular case of Beckett's later theater. The relations between memory and narrative in individual experience, as proposed by his play, are considered in the light of voiceover as a major staging device. Based on these elements, the article discusses the relevance of the concept of parody to Beckett's later theater.

KErWORDS: Samuel Beckett, Drama, Contemporary theater, Parody.

Luciano Gatti é doutor em Filosofia pela Universidade Estadual de Campinas (Unicamp) e professor do Departamento de Filosofia da Universidade Federal de São Paulo (Unifesp). Bolsista de Produtividade do CNPq. @ - lfgatti@gmail.com /

https://orcid.org/0000-0003-3960-3610

Recebido em 4.10.2019 e aceito em 5.11.2019.

I Departamento de Filosofia, Universidade Federal de São Paulo, Guarulhos, São Paulo, Brasil. 